\title{
DOORLICHTING VAN DIRECTIE EN DIRECTIEBELEID
}

\author{
door Dr. H. Coltof
}

\section{Ontwikkeling doorlichting}

In de laatste jaren vindt ook in Nederland de zogenaamde bedrijfsdoorlichting met als specifiek onderdeel daarvan de doorlichting van directiebeleid en topleiding (de zogenaamde ,management audit” of ..management appraisal”) in toencmende mate toepassing. Een tweetal factoren hebben hier sterk toe bijgedragen:

Enerzijds blijkt sinds 1960 steeds duidelijker dat ten aanzien van een belangrijk deel der Nederlandse middelgrote en grote ondernemingen, ja soms in gehele bedrijfstakken, een ingrijpende sanering en reorganisatie onvermijdelijk zal zijn. De oorzaken hiervan moeten binnen het bestek van ons onderwerp buiten beschouwing blijven. Anderzijds heeft de ontwikkeling van een sterk pluriforme organisatietheorie, zoals die zich met name buiten onze grenzen heeft afgespeeld, geleid tot het geleidelijk ter beschikking komen van een aantal redelijk betrouwbare onderzoek- en evaluatiemethodieken. Een vrij gevarieerd instrumentarium gebaseerd op onderzoek vanuit zeer verschillende wetenschappelijke disciplines kwam zodoende ter beschikking op een moment dat de behoefte aan praktische toepassing daarvan zich sterk deed gevoelen.

Het feit dat een belangrijk deel van het wetenschappelijk basisonderzoek en van de ervaringen met deze doorlichtingsmethodieken, in de USA waren gelocaliseerd heeft ertoe geleid dat de eerste toepassingen in ons land een typisch Amerikaanse inslag vertoonden. Te meer waar de onderzoeken zelf veelal ook door Amerikaanse organisatiebureaus werden uitgevoerd.

Nu enkele jaren zijn verstreken en ook door Nederlandse ,,management consultants" een ruimere ervaring op dit gebied is opgedaan, lijkt het mogelijk de twee essentieel verschillende omstandigheden aan te geven, die in een Nederlandse casu quo Europese omgeving sterk blijken te wegen namelijk:

1 impliciet en ook vaak expliciet gaan de Amerikaanse opvattingen en methoden uit van een veel hogere interne en externe mobiliteit van het midden- en topkader, dan in ons bedrijfsleven thans nog, wellicht zeer ten onrechte overigens, het geval blijkr;

2 bij de Amerikaanse benadering ligt de nadruk sterk op de analyse en op het opstellen van zogenaamde ,recommendations".

De eigenlijke ,implementatie” wordt als een relatief eenvoudig proces gezien.

$\mathrm{Nu}$ leert ervaring en onderzoek dat in het Europese bedrijfsklimaat ten aanzien van het snel en met succes doorvoeren van organisatorische veranderingen vaak grote weerstanden en vertragingen optreden. Voor een deel is dit wellicht weer toe te schrijven aan de genoemde geringere mobiliteit van het kader maar anderzijds zijn er mijns inziens duidelijke aanwijzingen dat hier ervaring en gewenning een grote rol spelen.

Bedrijven en bedrijfstakken met een hoge „rate of change” ontwikkelen duidelijk betere mogelijkheden tot effectieve organisatorische veranderingsprocessen 
dan in de gevallen waar ingrijpende reorganisaties slechts een zeer incidenteel voorkomend verschijnsel of zelfs een volkomen novum vormen.

Wellicht vormt het verschil in de ,rate of change" tussen het Amerikaanse en Europese bedrijfsklimaat mede een verklaring voor dit verschil in benadering.

Hoe dit ook moge zijn, de laatste jaren ziet zowel de Nederlandse directie als de Nederlandse ,management consultant" zich geconfronteerd met het verschijnsel van de bedrijfsdoorlichting.

Naar zijn inhoud en naar een aantal gebruikte technieken wellicht geen volkomen nieuw verschijnsel, maar wel nieuw gemeten naar de grote betekenis en zware nadruk die aan dit soort onderzoek thans wordt toegekend en naar de specifieke methodiek die met de term doorlichting wordt aangeduid.

\section{Grondslagen methodiek doorlichting}

De term doorlichting die mijns inziens sterk te prefereren zou zijn boven de term ,audit" welke ten onrechte reminiscenties oproept aan de accountantscontrole, geeft eigenlijk al twee specifieke kenmerken van de methodiek weer, namelijk:

- de toegepaste onderzoekmethoden en technieken zijn erop gericht om in relatief korte tijd een inzicht (inventaris, foto, opname) van de feitelijk aanwezige situatie te krijgen;

- de doorlichting is er niet op gericht om een beeld van de totale bedrijfssituatie te scheppen maar om een aantal structurele factoren (negatieve en positieve) te signaleren met name die welke bepalend kunnen zijn voor de toekomstige ontwikkeling.

Bij de bedrijfsdoorlichting hebben we te maken met een type organisatie-onderzoek waarbij bewust een beperking in tijd en in volledigheid van het onderzoek wordt nagestreefd, terwijl omgekeerd toch de betrouwbaarheid van de resultaten zoveel mogelijk gewaarborgd moet blijven.

De grondslagen waarop een dergelijke betrou wbare en verifieerbare onvolledigheid berust zijn in het algemeen geformuleerd de volgende:

a. De concrete bedrijfsorganisatie wordt benaderd als een ,open multi-level, multi-goal system” (mlmg-system). Als „open systeem”, dat wil zeggen: als afgezonderde sociaal-economische entiteit staat het bedrijf op vele punten in communicatie met zijn omgeving. Het is juist zijn strategie ten opzichte van die omgeving (afzetmarkten, concurrenten, inkoopmarkten, het sociale milieu, het institutionele kader waarin men is gevat etc.) die veelal bepalend is voor de eisen waaraan de organisatie in engere zin van dit systeem moet voldoen. Of zoals Juran het bondig heef $t$ uitgedrukt ,structure follows strategy".

Als systeem is de concrete bedrijfsorganisatie een geheel van een aantal delen die, hoewel qua invloed in het totaal en qua doeleinden verschillend, toch op een bepaalde wijze met elkaar samenhangen. Inzicht in dit systeem en in het functioneren daarvan blijkt mogelijk zonder dat gedetailleerd onderzoek van alle delen en van alle gebeurtenissen geschiedt. Een selectie hieruit levert al vrij snel een redelijk betrouwbaar beeld op van de strategische structurele opbouw van het systeem en van de betekenis der verschillende sub-systemen. 
b. Bij de hierboven aangegeven benadering van de organisatie als een ,,mlmg-system" past tevens een duidelijk onderzoek naar de aanwezige feitelijke machtsstructuur.

Het vaststellen van de in het systeem aanwezige ,power-structure" en van de grondslagen waarop deze berust, vormt een essentieel onderdeel van het onderzoek. Ook hier ligt weer een opmerkelijk verschil tussen de Amerikaanse en Nederlandse aanpak en literatuur. Het begrip macht of zelfs maar de vriendelijke afleiding hiervan in ,gezag als gelegimiteerde macht" en een behandeling van de betekenis hiervan en de factoren waarop zij berust, pleegt normaliter in de Nederlandse beschouwingen en handboeken te ontbreken. Toch is het slechts eerst na vaststelling van het feitelijke machtspatroon en de grondslagen daarvan mogelijk om te komen tot een evaluatie van het systeem en van het functioneren van de strategische functionarissen daarin.

c. Een derde grondslag sluit nauw aan bij het genoemde ,open” karakter van de bedrijfsorganisatie als afgezonderd sociaal-economisch systeem.

Het zal duidelijk zijn dat de beoordeling van de organisatie van een bedrijf als zodanig en de evaluatie van de strategische invloedrijke figuren in een open systeem alleen kan geschieden tegen de achtergrond van de eisen, die de omgeving (,environment") - dat wil zeggen het sociaal-economisch milieu waarin het bedrijf zich moet handhaven - stelt.

Het is aan dit pakket van eisen waaraan de bedrijfsorganisatie als doelorganisatie redelijk moet tegemoet komen wil zij kunnen blijven bestaan.

Op het niveau van de directie en van het directiebeleid gaat het daarbij niet zozeer om de eisen en potenties van het moment van onderzoek dan wel om de vraag hoe ziet dit beeld er op lange en middellange termijn uit.

Het opbouwen van een systematisch beeld van de ontwikkelingsmogelijkheden en beperkingen van de onderzochte organisatie op middellange termijn vormt dan ook een onmisbaar onderdeel van de bedrijfsdoorlichting. Slechts tegen deze achtergrond, via de lange-termijn-planning-methoden verkregen, kan een daarop afgestemde evaluatie van organisatie en topmanagement plaatsvinden.

Ook hier is dus sprake van een zekere onvolledigheid van het onderzoek in die zin dat primair de aandacht wordt gericht op de toekomstige ontwikkeling en op de dynamisch structurele factoren binnen en buiten de onderneming die daarop een duidelijke invloed zullen hebben.

Slechts een betrekkelijk beperkt gedeelte van de problemen van het heden blijken dan relevant. Er vindt een selectie via de tijdsdimensic van de verschillende factoren, problemen en potenties plaats, die overigens in overeenstemming is met de tijdsdimensie waarin de topleiding van het moderne bedrijf geacht wordt te denken. ( 5 a 10 jaar respectievelijk in sommige gevallen 10 à 20 jaar).

Het is overigens duidelijk dat ten aanzien van dit type beleidsproblemen de bijdrage van de sociale economie, met name van de macro-economische planning van toenemend belang wordt.

Reeds jaren doet zich op het gebied van de problemen van ondernemingsbeleid en in de organisatietheorie een verschuiving voor, waarbij enerzijds de betekenis van de bedrijfseconomie sterk dalende is (ook al omdat op dit vroeg geëxploreerde gebied de wet van de afnemende meeropbrengst zich sterk doet gevoelen) ander- 
zijds de betekenis van vele andere nieuwere disciplines en van de moderne sociale economie snel toeneemt.

\section{Doorlichtingsmethoden en technieken}

In het voorgaande heb ik geprobeerd een verklaring te geven van de grondslagen waarop de doorlichtingsmethodiek berust. Een verklaring van de mogelijkheid tot betrouwbare onvolledigheid of met een variant op een uitspraak van Simon, een aanduiding dat de wereld van het doorlichtingsonderzoek betrekkelijk „leeg” kan zijn. Evenals schrijven is onderzoeken ,,selectief weglaten".

Proberen wij thans ter afsluiting een, binnen het kader van een tijdschriftartikel uiteraard beperkte, aanduiding te geven van methoden en technieken.

a. Het onderzoek van het directiebeleid maakt gebruik van de verschillende instrumenten op het gebied van de lange termijn planning en de zogenaamde "corporate planning", zoals die ook in onze ondernemingen geleidelijk ingang vinden. Het is gericht op het bepalen van de mogelijke strategieën en op een bewuste keuze uit alternatieve strategieën. Eerst tegen deze achtergrond kan een evaluatie van de organisatie-structuur, de bezetting van de sleutelpositie en de beoordeling van tactische procedures geschieden.

De noodzaak hiertoe springt in het oog indien men het schouwspel gadeslaat van bedrijven die met handhaving of soms onbewust van een volledig onjuiste strategie, zich op het tactische vlak grote inspanningen tot verbetering getroosten. Het is dit risico van efficiency tot de dood erop volgt, waarop de hiergenoemde benadering een correctief zou kunnen vormen.

b. Het onderzoek van de organisatie in engere zin, opgevat als systeem, maakt gebruik van een groot aantal uiteenlopende methoden en technieken. Uiteenlopend niet alleen naar hun graad van betrouwbaarheid maar tevens soms essentieel verschillend, gezien hun herkomst vanuit zeer verschillende disciplines. Hier kan alleen de harde praktijk leren wat instrumentaal en relevant is en wat logisch fraaie theorie blijft. Hier zullen ook de individuele ervaringen en beperkingen van onderzoekers een grote rol spelen.

Daarbij blijkt de benadering van het bedrijf als dynamisch systeem, waarbij het onderzoek gericht wondt op de verschillende organisatorische processen, in de praktijk zeer effectief te zijn. Bovendien blijkt het mogelijk de verschillende gebruikte technieken enigzins te classificeren naar aard van organisatorisch proces. Schematisch zou men deze gedachte als volgt kunnen voorstellen:

\begin{tabular}{|c|c|c|c|}
\hline $\begin{array}{l}\text { Organisatorische pro- } \\
\text { cessen }\end{array}$ & $\begin{array}{l}\text { Waarnemings- } \\
\text { methodieken }\end{array}$ & $\begin{array}{l}\text { vastleggingsmetho- } \\
\text { dieken }\end{array}$ & $\begin{array}{l}\text { wetenschappelijke } \\
\text { achiergronden }\end{array}$ \\
\hline $\begin{array}{l}\text { a. werkstroom/arbeids- } \\
\text { stro' oces } \\
\text { (workflow) }\end{array}$ & $\begin{array}{l}\text { check-lists } \\
\text { svstematische inter- } \\
\text { vieuws } \\
\text { t1justudie } \\
\text { werkmethode analyse } \\
\text { verkorte tijdstudie- } \\
\text { systemen (MTM, MCD } \\
\text { e.d.) } \\
\text { multi momentopnamen } \\
\text { produktiegegevens } \\
\text { kwaliteitscontrole ge- } \\
\text { gevens }\end{array}$ & $\begin{array}{l}\text { proces analyse bladen } \\
\text { flow-charts } \\
\text { formulier diagrammen } \\
\text { frequentie tabellen } \\
\text { behandelingsschema's } \\
\text { interview protocollen } \\
\text { tijd-weg-schema's } \\
\text { planning en netwerk- } \\
\text { planning schema's } \\
\text { kwantitatieve over- } \\
\text { zichten } \\
\text { lay-out en routing } \\
\text { schema's }\end{array}$ & $\begin{array}{l}\text { scientific-management } \\
\text { organisatiekunde } \\
\text { technische wetenschap- } \\
\text { pen } \\
\text { administratieve organi- } \\
\text { satie } \\
\text { statistiek }\end{array}$ \\
\hline
\end{tabular}




\begin{tabular}{llll}
\hline $\begin{array}{l}\text { Organisatorische } \\
\text { processen }\end{array}$ & $\begin{array}{l}\text { Waarnemings- } \\
\text { methodieken }\end{array}$ & $\begin{array}{l}\text { Vastleggings- } \\
\text { methodieken }\end{array}$ & $\begin{array}{l}\text { wetenschappelijke } \\
\text { achtergronden }\end{array}$
\end{tabular}

\section{b. het communicatie} proces open interviews enquêtes en dergelijke individuele opnamen groepswaarneming participerende waarneming incident-methode veldmodellen interview protocollen sociogrammen preferentie schalen $\mathrm{kwalitatieve} \mathrm{en} \mathrm{kwan}$ titatieve interactie over- statistiek zichten theorie sociologie

moderne informatiesociale psychologie organisation research communicatie-experimenten semantische studies computer simulatie

c. processen die tot interne structurering leiden (functie- en taakvorming, hiërarchering, beloning. en/of sancties kruis-interviews participerende waarneming incident-methode trainings laboratoria „,klimaat" onderzoek produktiviteits- en effectiviteitsstudies organisatie schema's functie- en taakbeschrijvingen organisatje manuals veldmodellen primaire en secundaire beloningsoverzichten vastleggen bedrijfscultuur en normstelsel produktiviteits- en effectiviteitsoverzichten scientific management sociologie sociale-psychologie groepsdynamica modern personeelsbeleid behavioral sciences bedrijfseconomie

specifieke overzichten behavioral sciences preferentie schalen

d. evaluatie interne specifieke onderzoekstructurering (status- methoden en enquêtes vorming, identifica- recrutering en verlooptieprocessen en der- cijfers gelijke)

sociale afstandsoverzichten

e. synthetische processen besluitvormings

bevoegdheidsschema's besluitvormings-centra machtsconcentraties proces pressure-groups centralisatie/decentrali- turen satie delegatie

veldmodellen

theoretische modellen decision centers besluitvormings-struc- policy-statements statuten en publicaties budget analyse public relations materiaal

interne en externe bedrijfspublicaties inventaris schema's en beschikbaar materiaal

budgetten

lange termijn planning sociale psychologie behavioral sciences groepsdynamica O.R./besliskunde informatie-theorie politiek sociale economie politiek administratieve organisatie public-relations sociale psychologie 8. Continuiteit/perpe-
tueringsproces analyse personeelsopbouw kwantitatief $\mathrm{kwalitatief}$ management-development personeelsplanning training programma's beoordelingssystemen mobiliteitsstudies

- planning op langere termijn ten aanzien van economische en technische ontwikkeling

- marketing planning wie volgt ons op schema's lange termijn planning evaluatie-overzichten mobiliteitsoverzichten economie modern personeelsbeleid LTP-theorie toekomstkunde 
Uit het onderzoek van deze organisatorische processen ontstaat dan vrij snel een inzicht in het feitelijke functioneren, met name van het hogere kader en de topleidingen, en in de aanwezige "power-structure”.

Gezien de aard van dit type onderzoek blijkt dit in de praktijk alleen met interdisciplinair opgebouwde teams van onderzoekers goed uitvoerbaar.

c. Eén der meest hachelijke maar onontkoombare onderwerpen bij de doorlichting van het directiebeleid is de evaluatie van het hogere kader en de directie zelf. Waar dit onderwerp op zichzelf een afzonderlijk artikel zou rechtvaardigen moet ik hier volstaan met een tweetal korte notities:

- de ontwikkelde onderzoekmethoden geven momenteel een redelijk betrouwbare mogelijkheid tot evaluatie van de capaciteiten en mogelijkheden van strategische functionarissen. Een uitermate moeilijke zaak blijft echter het projecteren van de mogelijkheden van dergelijke functionarissen in een gewijzigde casu quo toekomstig veranderende situatie.

In het kader van de „management appraisal” is juist vaak van deze laatste situatie sprake.

- anderzijds lijkt en geen enkele reden aan te nemen dat de top van het Nederlandse bedrijfsleven niet zou zijn opgewassen tegen de confrontatie met de eisen van de toekomst en met zichzelf, die uit de bedrijfsdoorlichting naar voren komt. Dat dit zware eisen stelt aan de persoonlijke integriteit en het verantwoordelijkheidsbesef zowel van directies als van de management adviseurs moet men zich in het concrete geval van de aanvang af scherp en duidelijk voor ogen stellen.

\section{Slot}

Een enkele korte opmerking tot slot.

Welke taxatie men ook heeft van de kracht of zelfs maar het bestaan van de ,le defi Americain", de uitdaging die de moderne industriële maatschappij vormt, kan niemand ontgaan.

De strategieën en methoden van de Amerikaanse grote bedrijven, zoals wij die thans in Europa zien opereren, zijn in die zin wellicht niet zozeer Amerikaans dan wel een geavanceerde vorm van bedrijfsvoering die op die komende industriële maatschappij is afgestemd.

$\mathrm{Nu}$ is er mijns inziens maar één werkelijk dominerende factor bepalend, voor de toekomstige ontwikkeling, namelijk: kunnen wij leren? Kunnen wij ons losmaken van vroegere en dierbare opvattingen en ons openstellen ten aanzien van de eisen van morgen? Kunnen wij op het moment dat we te dogmatisch, te zeker zijn, ons het woord van Multatuli herinneren dat "niets helemaal waar is, en zelfs dat niet" en er naar leven?

In die fundamentele zin is de $\mathrm{zg}$. "management development" niet alleen van toepassing op een bepaalde leeftijdsgroep of niveau in onze organisaties, maar van blijvende noodzaak juist ook voor de topleiding.

De resultaten van de bedrijfsdoorlichting confronteren die topleiding in menig geval met een situatie waarin de kwaliteit van de organisatie en haar eigen functioneren is achtergebleven bij de eisen die daaraan entern en intern worden gesteld. Het organisatorische veranderingsproces om opnieuw aan deze eisen aanpassing 
te vinden, kan dan moeilijk zijn. Het houdt niet alleen de toepassing van meer moderne organisatie opvattingen en methoden in maar neemt voor de topleiding, als groep en individueel, de vorm van een leerproces aan. Juist de bereidheid van een directie om dan ook zelf in de ,poetsmolen" te gaan, blijkt veelal bepalend te zijn voor het nuttig rendement van de bedrijfsdoorlichting. 